\title{
The in vitro and in vivo effects of clofazimine on the motility of neutrophils and transformation of lymphocytes from normal individuals
}

\author{
E M S GATNER*§, R ANDERSON†, \\ C E VAN RENSBURG† \& \\ FLORENTINE M J H IMKAMP \\ *The Department of Microbiology, Medical University of \\ Southern Africa; ${ }^{\dagger}$ The Immunology Section, Department of \\ Medical Microbiology, University of Pretoria; $\$$ Westfort Hospital, \\ Pretoria, Republic of South Africa
}

Received for publication 6 July 1981

Summary The effects of clofazimine on neutrophil motility to endotoxinactivated serum and mitogen-induced lymphocyte transformation of leucocytes from normal individuals in vitro, and after ingestion of clofazimine by normal adult volunteers have been assessed. Clofazimine caused a progressive dose-dependent inhibition of neutrophil motility and of lymphocyte transformation in vitro. Ingestion of the drug by normal volunteers was accompanied by decreased neutrophil motility and lymphocyte transformation to mitogens. These findings suggest that the antiinflammatory properties of clofazimine are related to inhibition of these cellular immune functions.

\section{Introduction}

The antimicrobial therapy of leprosy is more complicated than that of other acute or chronic bacterial infections. This is due to the development of adverse immunological reactions which may accompany chemotherapy. The conditions associated with these reactions are referred to as erythema nodosum leprosum (ENL) and the reversal reaction caused by types III and IV immunological hypersensitivity reactions respectively. These complications probably develop

$\S$ Correspondence: DrE M S Gatner, The S.A. Breweries Ltd, Central Laboratory, P.O. Box 10, Isando 1600, South Africa. 
due to two related factors: (a) the extremely high antigen load found in patients with the lepromatous form of the disease and (b) the high degree of diseaseassociated immunosuppression, i.e. specific anergy to lepromin ${ }^{1}$ and decreased neutrophil motility. ${ }^{2}$ Drug-induced ENL is probably due to the destruction of leprosy bacilli with the formation of localized and circulating immune complexes and the development of tissue damage mediated by the phagocytecomplement system. Likewise, the decreased antigen load which accompanies successful antimicrobial therapy may result in a decrease in the specific unresponsiveness to the leprosy antigens with activation of hitherto suppressed antigen-specific T-lymphocytes. This may cause increased macrophage recruitment with resultant tissue damage due to cell-mediated mechanisms. These complications could develop solely as a consequence of the antimicrobial activity of drugs used in patients with leprosy.

However, a second more direct mechanism of induction of chemotherapyassociated hypersensitivity reactions may occur if the chemotherapeutic agents per se possess immunostimulatory activity as has previously been reported for dapsone. ${ }^{3,4}$ This agent was found to cause stimulation of neutrophil motility and a possible role for this drug in the pathogenesis of some cases of ENL suggested. ${ }^{3}$ There are reports that clofazimine is useful in the treatment of some cases of ENL ${ }^{5,6}$ and in controlling some reversal reactions. ${ }^{6,7}$ It has been shown in animal studies that clofazimine may possess anti-inflammatory properties $^{8}$ although the precise mechanisms of this are unknown.

In this study we have investigated the effects of clofazimine on neutrophil motility and lymphocy te transformation in normal individuals in vitro and in vivo.

\section{Materials and methods}

Clofazimine (B663, lamprene) pure substance for in vitro studies and $100 \mathrm{mg}$ capsules for in vivo studies was kindly donated by Ciba-Geigy (Pty) Ltd, Johannesburg. For in vitro studies the drug was solubilized in dimethylsulphoxide (DMSO) to give a concentration range of $10^{-6} \mathrm{M}$ to $10^{-3} \mathrm{M}$ (equivalent to 0.3 to $300 \mu \mathrm{g} / \mathrm{ml}$ ) in Hanks' balanced salt solution (HBSS) for studies of motility, and TC199 for lymphocyte studies. (Both HBSS and TC199 were obtained from the Grand Island Biological Co., Grand Island, NY, USA). Control systems containing the corresponding DMSO dilution only were included for each clofazimine concentration tested, i.e. 0.0015 to $1.5 \%$ DMSO for $10^{-6} \mathrm{M}$ to $10^{-3} \mathrm{M}$ clofazimine. For in vivo studies 6 normal adult volunteers ingested $2 \times 100 \mathrm{mg}$ capsules of clofazimine as a single oral, daily dose for 5 days. Tests of neutrophil motility and lymphocyte transformation were performed prior to the ingestion of clofazimine, at $2 \mathrm{~h}$ and at $24 \mathrm{~h}$ after ingestion of a single oral dose of $200 \mathrm{mg}$ clofazimine and on the 5th day of ingestion of $200 \mathrm{mg}$ of clofazimine daily (testing was performed $2 \mathrm{~h}$ after ingestion of the last dose). 
Neutrophil motility. Neutrophils were obtained from heparinized blood (5 units of heparin $/ \mathrm{ml}$ ) from normal adult volunteers and were resuspended to a final concentration of $3 \times 10^{6} / \mathrm{ml}$ in HEPES (N-2-hydroxyethyl-piperazine$\mathrm{N}^{\prime}$-2-ethanesulphonic acid obtained from the Sigma Chemical Co., St. Louis, Mo., USA) buffered HBSS following hypotonic lysis of residual erythrocytes with $0.84 \%$ ammonium chloride as previously described. ${ }^{9}$ The leucoattractant used was endotoxin-activated serum (EAS). Fresh autologous serum was activated with $100 \mu \mathrm{g}$ bacterial endotoxin per $\mathrm{ml}$ (Escherichia coli $0127: \mathrm{B} 8$, Difco Laboratories, Detroit, Mich., USA) and diluted 8-fold with HBSS before use. The assays of motility were performed in modified Boyden chambers ${ }^{10}$ using $5 \mu \mathrm{m}$-pore size membrane filters (Sartorius-membranfilter, Göttingen, West Germany) and a 2-h incubation period. The results are expressed as the number of cells which have completely crossed the filter, per microscope highpowered field as an average of triplicate filters.

Lymphocyte transformation. Blood for studies of lymphocyte function was defibrinated and fractionated by density gradient centrifugation (Ficoll-sodium metrizoate) at $400 \mathrm{~g}$ for $25 \mathrm{~min}$. The mononuclear cells were washed twice in TC199 and resuspended to $4 \times 10^{6} / \mathrm{ml}$ in TC199 supplemented with $20 \%$ autologous serum; $2 \times 10^{5}$ cells were used in the assay system which was done as previously described using phytohaemagglutinin (PHA) and concanavalin A (Con A) as the mitogens at concentrations of 25 and $50 \mu \mathrm{g} / \mathrm{ml}^{9}{ }^{9}$

\section{Results}

The results are expressed as the mean value with standard error for 6 separate experiments for in vitro studies and 6 different individuals for in vivo studies. Statistical analyses were performed by Student's t-test for paired means.

Neutrophil motility. Clofazimine at concentrations greater than $5 \times 10^{-6} \mathrm{M}$ in vitro caused a progressive inhibition of neutrophil motility to EAS. These results are shown in Table 1. DMSO at all concentrations used had no significant effect on motility to EAS (results not shown). No effect on neutrophil motility to EAS was observed $2 \mathrm{~h}$ after ingestion of clofazimine by the group of normal individuals. However, a consistent slight inhibition of motility was observed $24 \mathrm{~h}$ af ter the ingestion of a single oral $200 \mathrm{mg}$ dose of clofazimine and on the 5 th day of clofazimine ingestion. This difference did not achieve statistical significance. These results are shown in Table 2.

Lymphocyte transformation. Incubation of lymphocytes with clofazimine at concentrations greater than $10^{-5} \mathrm{M}$ in vitro caused inhibition of lymphocyte responsiveness to both mitogens at both concentrations (Table 1). DMSO, at a concentration of $1.5 \%$, contained in the $10^{-3} \mathrm{M}$ clofazimine system, caused inhibition of transformation. Lower concentrations had no detectable effects on the assay system. Ingestion of clofazimine was accompanied by a 
Table 1. The effects of clofazimine on neutrophil motility to EAS and lymphocyte transformation to PHA and Con A in vitro

\begin{tabular}{cccc}
\hline $\begin{array}{c}\text { Clofazimine } \\
\text { concentration }\end{array}$ & $\begin{array}{c}\text { Neutrophil motility } \\
\text { to EAS }\end{array}$ & \multicolumn{2}{c}{ Lymphocyte transformation to } \\
PHA $(25 \mu \mathrm{g} / \mathrm{ml})$ & Con A $(50 \mu \mathrm{g} / \mathrm{ml})$ \\
\hline Control & $143 \pm 26 \dagger$ & $57,841 \pm 9,775 \ddagger$ & $8,830 \pm 4,767 \ddagger$ \\
$10^{-3} \mathrm{M}$ & $35 \pm 10^{* *}$ & N.S. $\S$ & N.S. \\
$10^{-4} \mathrm{M}$ & $70 \pm 13^{* *}$ & $30,536 \pm 7,063^{*}$ & $1,764 \pm 696^{*}$ \\
$10^{-5} \mathrm{M}$ & $121 \pm 23^{*}$ & $59,278 \pm 11,817$ & $7,497 \pm 3,583$ \\
\hline
\end{tabular}

$\dagger$ Results as mean neutrophils/microscope high-powered field with standard error for 6 experiments.

$\ddagger$ Results as mean radioactive counts per minute with standard error for 3 experiments.

$\S$ Results not shown due to the inhibitory effects of DMSO on the reaction system.

$* P<0.05$.

$* * P<0.01$.

Table 2. The effects of ingestion of clofazimine by 6 normal adult volunteers on neutrophil motility to EAS and lymphocyte transformation to PHA and Con A

\begin{tabular}{|c|c|c|c|c|}
\hline \multirow{2}{*}{\multicolumn{2}{|c|}{ Time of testing }} & \multirow{2}{*}{$\begin{array}{l}\text { Neutrophil motility } \\
\text { to EAS }\end{array}$} & \multicolumn{2}{|c|}{ Lymphocyte transformation to } \\
\hline & & & PHA $(25 \mu \mathrm{g} / \mathrm{ml})$ & Con A $(25 \mu \mathrm{g} / \mathrm{ml})$ \\
\hline 1 & $\begin{array}{l}\text { Before ingestion of } \\
\text { clofazimine }\end{array}$ & $192 \pm 29 \dagger$ & $59,339 \pm 5,233 \ddagger$ & $6,968 \pm 1,119$ \\
\hline 2 & $\begin{array}{l}2 \mathrm{~h} \text { after the ingestion of } \\
\text { a single oral dose of }\end{array}$ & & & \\
\hline & $200 \mathrm{mg}$ clofazimine & $177 \pm 41$ & $28,021 \pm 3,305^{*}$ & $3,237 \pm 446 * *$ \\
\hline 3 & $\begin{array}{l}24 \mathrm{~h} \text { after ingestion of a } \\
\text { single oral dose of }\end{array}$ & & & \\
\hline & $200 \mathrm{mg}$ clofazimine & $135 \pm 35$ & $55,508 \pm 3,245$ & $4,502 \pm 560$ \\
\hline 4 & On the 5th day of & & & \\
\hline & $\begin{array}{l}\text { ingestion of } 200 \mathrm{mg} \text { of } \\
\text { clofazimine daily }\end{array}$ & $165 \pm 34$ & $45,985 \pm 3,603^{*}$ & $4,127 \pm 474^{*}$ \\
\hline
\end{tabular}

$\dagger$ Results as mean neutrophils per microscope high-powered field with standard error for 6 in dividuals.

$\ddagger$ Results as mean radioactive counts per minute with standard error for 6 individuals. $* P<0.05$.

$* * P<0.01$.

decreased lymphocyte response to both mitogens in each individual tested. The inhibitory effects on transformation were detected $2 \mathrm{~h}$ after the ingestion of a single $200 \mathrm{mg}$ oral dose of clofazimine and on the 5th day of ingestion of clofazimine. The lymphocyte transformation to PHA returned to normal values $24 \mathrm{~h}$ after the ingestion of a single oral dose of $200 \mathrm{mg}$ clofazimine. These results are shown in Table 2. 


\section{Discussion}

In this study we have found that clofazimine causes inhibition of neutrophil motility to EAS and of lymphocyte proliferation to mitogens in vitro and in vivo. Although the observed changes in neutrophil motility in vitro following exposure to clofazimine in vivo were not significant, they were consistently found and we believe that this is a true effect of clofazimine. These findings support to some extent previous reports that clofazimine may be of value in the treatment of ENL ${ }^{5,6}$ and reversal reactions. ${ }^{6,7}$ However, this does not exclude the possibility that in some cases clofazimine may precipitate these reactions by virtue of its ability to cause antigen release through antimicrobial mechanisms. Nevertheless, as a result of its immuno-inhibitory activity clofazimine therapy should be accompanied by considerably fewer adverse immunological reactions than dapsone, which possesses immunostimulatory activity. Clofazimine should therefore be considered to be a useful agent in the antimicrobial therapy of those patients undergoing serious immunological reactions or those who may be prone to developing such reactions since it will not counteract the therapeutic activity of prescribed antiinflammatory or immunosuppressive agents. Indeed it could be expected to enhance their activity.

In describing the immunological effects of clofazimine we prefer to use the term immuno-inhibitory rather than anti-inflammatory. The use of the term anti-inflammatory is often taken as being synonymous with immunosuppressive. However, we feel that this implication is not necessarily correct. Indeed dapsone, which is used in a variety of dermatological conditions as an 'antiinflammatory' agent, ${ }^{11}$ has been found to possess non-specific immunostimulatory activity. ${ }^{4}$ It is therefore possible that in some cases anti-inflammatory agents may possess immunostimulatory activity. This concept seems difficult to reconcile. Nevertheless, it is possible that dapsone by virtue of its ability to protect leucocyte membranes from auto-oxidation which causes marked inhibition of locomotion ${ }^{4}$ may permit leucocytes, especially neutrophils, to enter inflammatory zones, phagocytose immune complexes and leave these zones. However, if they enter the zones and undergo strong auto-oxidation during function they may become immobilized and further contribute to tissue damage and chronic inflammation by release of proteolytic enzymes and toxic oxygen radicals. ${ }^{12}$ This theory could rationalize the anti-inflammatory activity of dapsone in some conditions and its possible pro-inflammatory activity in ENL in which it may enhance the phagocyte response to chronic antigen release.

Clofazimine, as shown in this study, has the opposite effect to dapsone, i.e. it causes inhibition of neutrophil motility and lymphocyte transformation. These findings may explain the mechanism by which clofazimine is of value in the treatment of some ENL and reversal immunity reactions. 


\section{References}

${ }^{1}$ Godal T, Myrvang B, Froland SS, Shao J, Melaku G. Evidence that the mechanism of immunological tolerance (central failure) is operative in the lack of host resistance in lepromatous leprosy. Scand J Immunol 1972; 1: 311.

${ }^{2}$ Bullock WE, Ho MF, Chen MJ. Quantitative and qualitative studies of the local cellular exudative response in leprosy. J Reticuloendothel Soc 1974; 16:259.

${ }^{3}$ Anderson R, Gatner EMS. Changes in neutrophil motility accompanying dapsone and rifampicin therapy. Lepr Rev 1980; 52:19.

${ }^{4}$ Anderson R, Gatner EMS, Van Rensburg CE, Grabow G, Imkamp FMJH, Kok SH Van Rensburg AJ. In vitro and in vivo effects of dapsone on neutrophil and lymphocyte functions in normal individuals and patients with lepromatous leprosy. Antimicrob Ag Chemother 1981; 19:495.

${ }^{5}$ Imkamp FMJH. A treatment of corticosteroid-dependent lepromatous patients in persistent erythema nodosum leprosum. A clinical evaluation of G. 30320 (B663). Lepr Rev $1968 ; 39: 119$.

${ }^{6}$ Schulz J. 44 months' experience in the treatment of leprosy with clofazimine. Lepr Rev $1971 ; 42: 178$.

${ }^{7}$ Pfaltzgraff RE. The control of neuritis in leprosy with clofazimine. Int J Lepr 1972; 40:392.

${ }^{8}$ Vischer WA. The experimental properties of G30 320 (B663) - a new anti-leprotic agent. Lepr Rev 1969; 40:107.

${ }^{9}$ Anderson R, Oosthuizen R, Theron A, Van Rensburg AJ. The in vitro evaluation of certain neutrophil and lymphocyte functions following the ingestion of a $150 \mathrm{mg}$ oral dose of levamisole. Clin Exp Immunol 1979; 39:478.

10 Wilkinson PC. Chemotaxis of phagocytic cells towards proteins: the effects of protein denaturation. In: Di Luzio NA, Flemming K, eds. The Reticuloendothelial System and Immune Phenomena. New York: Plenum Press, 1981: 59.

11 McDougall AC. Dapsone. Clin Exp Dermatol 1979; 4:139.

12 Sacks T, Moldow CF, Craddock PR, Bowers TK, Jacob HS. Oxygen radicals mediate endothelial cell damage by complement-stimulated granulocytes. An in vitro model of immune vascular damage. J Clin Invest 1978; 61:1161. 